\title{
Relationship between Health Literacy and Adherence to Recommendations to Undergo Cancer Screening and Health-Related Behaviors among Insured Women in Japan
}

\author{
Eiko Goto*, Hirono Ishikawa, Tsuyoshi Okuhara, Takahiro Kiuchi
}

\begin{abstract}
Background: Health literacy serves as a major barrier to effective preventive health behaviors, such as cancer screening, and this relationship has not been studied among insured women in Japan. We examined the relationship between health literacy and adherence to recommendations to undergo cancer screening, and health-related behaviors, among Japanese women who were insured by a health insurance society. Methods: We conducted a cross-sectional observation study of 670 insured Japanese women. For this, we used a self-administered questionnaire to assess environments, self-rated health status, cancer screening behavior, health-related behaviors (dietary behavior, exercise frequency, alcohol consumption and smoking behavior), and health literacy. Results: Among the participants, 206 completed the questionnaire (response rate, 30.7\%). Fifty-seven had undergone breast and/or cervical cancer screening. The mean health literacy score was 3.44 (standard deviation $=0.68$ ). In logistic regression models adjusted for age, self-rated economic status, and having a primary care physician, there was no statistically significant relationship between health literacy and adherence to recommendations to undergo cancer screening, and health-related behaviors. However, age and having a primary care physician were significantly associated with cancer screening and health-related behaviors. Health literacy was not found significantly associated with effective preventive health behaviors. Conclusions: The present study found no statistically significant relationship between health literacy and adherence to recommendations to undergo cancer screening and health-related behaviors. Rather, cancer screening and health-related behaviors were found related to medical support from physicians and those their own age. Further study is needed for exploring these associations among insured women in Japan.
\end{abstract}

Keywords: Health literacy- cancer screening- health-related behavior- Japanese women

Asian Pac J Cancer Prev, 19 (12), 3409-3413

\section{Introduction}

Breast cancer and cervical cancer are major worldwide health problems for women. It is well known that screening for these cancers correlates with better health outcomes, such as lower disease incidence and lower mortality rates (Myers et al., 2015; Di et al., 2015). Despite this, breast and cervical cancer screening rates in Japan are lower than those in some Western countries (OECD. Stat, 2013). Japan has universal healthcare insurance coverage under a public insurance scheme. Most insurers provide breast and cervical cancer screening for insured Japanese women, and with a low, or no, copayment. Nonetheless, it has been widely acknowledged that screening recommendations are not necessarily followed.

Recently, health literacy has come to be considered an important factor behind individual health behaviors and outcomes. The World Health Organization defines it as "the cognitive and social skills which determine the motivation and ability of individuals to gain access to, understand, and use information in ways which promote and maintain good health" (Nutbeam, 1998). Many reports have found that people with limited health literacy may be unable to adequately understand and utilize health information in ways that protect and improve their health, and that they consequently have lower health status and lower cancer screening rates (Davey et al., 2015; Liu et al., 2015; Duong et al., 2015; Delanoë et al., 2016; Kim et al., 2016; Oldach et al., 2014).

Nutbeam proposed a health literacy model comprising three levels: (1) functional literacy-sufficient basic skills in reading and writing; (2) communicative literacy-skill in applying new information; and (3) critical literacyskill in critically analyzing information with respect to life events and situations (Nutbeam, 2000). Although few studies have examined health literacy beyond a functional level, previous studies in Japan have reported that higher communicative and critical health literacy 
were associated with healthy lifestyles, greater efficacy at coping with job stress, and better health status, such as fewer somatic symptoms and better self-rated health (Ishikawa et al., 2008; Furuya et al., 2013). However, no studies have explored associations of health literacy beyond a functional level with regard to adherence to recommendations for insured Japanese women to undergo breast and cervical cancer screening.

The present study aimed to examine the relationship between health literacy and adherence to recommendations to cancer screening, and health-related behaviors, among Japanese women who were insured by a health insurance society in the country.

\section{Materials and Methods}

\section{Study settings and sampling}

The present study was conducted among Japanese women insured through a health insurance society of a Japanese industrial service company. The society in April 2016 in a magazine for the insured posted a recommendation for cancer screening. Among 1,216 Japanese women, 546 (44.9\%) had obtained breast and/or cervical cancer screening at hospitals or clinics affiliated with the society by the end of September 2016. In this cross-sectional observational study, we recruited the remaining 670 who had not received screening. Among them, 206 who completed our questionnaire (response rate, $30.7 \%$ ) were the sample for this study.

We obtained details on age, education, occupation, having a primary care physician, and self-rated economic status. The latter was ranked on a five-point scale, ranging from 1 (lowest status) to 5 (highest status). We categorized these as "low" (1-2 points), "middle" (3 points), or "high" (4-5 points). Based on methods in a previous study, we asked the participants to assess their self-rated health status on a scale ranging from 1 (low) to 5 (high) (Matsumoto et al., 2004). We categorized as "low" (1-2 points), "middle" (3 points), "high" (4-5 points). We also assessed whether the participants had undergone breast and/or cervical cancer screening since April 2016.

We measured health literacy using the Communicative and Critical Health Literacy scale (Ishikawa et al., 2008), which was developed based on the dimensions of health literacy described earlier (Nutbeam, 2000). This scale was comprised three items for communicative health literacy and two for critical health literacy. The scores of the five items were summed and divided by five to yield a scale score (theoretical range, 1-5). The internal consistency of the scale was found to be adequate (Cronbach's $\alpha=0.86$ ).

Using a self-administered questionnaire based on the National Health and Nutrition Survey 2016, we asked participants about their health-related behaviors, such as dietary behavior (have a well-balanced diet every day, not every day), exercise frequency (2 times or more per week, 1 time or less per week), alcohol consumption (every day, not every day) and smoking behavior (current smoker, not current smoker).

The present study received the ethics approval by the ethical review committee at Graduate School of Medicine, The University of Tokyo (examination number 11338).

\section{Statistical analysis}

Because health literacy scores showed non-normal distribution, we first conducted a Kruskal-Wallis test to determine the bivariate association between the independent variables and health literacy. We then employed logistic regression analysis to test the relationship of health literacy with cancer screening behavior and health-related behaviors, adjusting for age, self-rated economic status, and having a primary care physician. A P value of $<.05$ was set as significant for all statistical tests. Data analyses was conducted using SPSS Statistics for Windows, Version 21.0 (IBM Corp, Armonk, NY, USA).

\section{Results}

Table 1 presents the participants' characteristics and descriptive results of the study variables. The mean age was 45.9 years (standard deviation $[\mathrm{SD}]=10.5$ ). In all, $38.8 \%$ of the participants had graduated vocational school or junior college and $51.9 \%$ were not working. The majority of the participants were high self-rated health status, which accounted for $68.9 \%$ of this study group. Regarding health-related behaviors, $38.8 \%$ of the participants had well-balanced diet every day and $18.4 \%$ exercised 2 times or more per week. $31.1 \%$ of the participants drank alcohol every day and smoking rate was $11.7 \%$. The mean health literacy score was 3.44 $(\mathrm{SD}=0.68)$. Those who underwent breast and/or cervical cancer screening accounted for $27.7 \%$. Health literacy was found significantly associated with self-rated economic status and having a primary care physician $(\mathrm{P}=.018$, $\mathrm{P}=0.005$, respectively). However, it was not significantly associated with cancer screening behavior. Among the four health-related behaviors, health literacy was significantly positively associated with dietary and exercise behavior $(\mathrm{P}=0.026, \mathrm{P}=.025$, respectively).

Table 2 shows the logistic regression analyses of health literacy on cancer screening behavior and health-related behaviors. After adjusting for age, self-rated economic status, and having a primary care physician, there was no statistically significant relationship found between health literacy and cancer screening behavior and all healthrelated behaviors. Despite there being no relationship with cancer screening behavior, those who had a primary care physician were more likely to undergo cancer screening (adjusted odds ratio $[\mathrm{OR}]=2.288 ; 95 \%$ confidence interval [CI], 1.142-4.583). Regarding health-related behaviors, age was significantly associated with exercise behavior (adjusted OR $=1.060 ; 95 \% \mathrm{CI}, 1.021-1.101$ ).

\section{Discussion}

This study explored the relationship between health literacy and adherence to recommendations to cancer screening and health-related behaviors among Japanese women who were insured by a health insurance society. The mean score for health literacy was $3.44(\mathrm{SD}=10.5)$, which was lower than that was reported in a previous study of male Japanese workers $(\mathrm{N}=190$, mean $\pm \mathrm{SD}$; $3.72 \pm 0.68$ ) (Ishikawa et al., 2008). It is also lower than 
Table 1. Characteristics and Health Literacy of Study Participants (N=206)

\begin{tabular}{|c|c|c|c|c|c|}
\hline & \multirow{2}{*}{$\begin{array}{c}\text { Total } \\
\mathrm{N}\end{array}$} & \multicolumn{3}{|c|}{ Health literacy } & \multirow{2}{*}{$\begin{array}{c}\text { "Kruskal-Wallis test } \\
\mathrm{p}\end{array}$} \\
\hline & & $\%$ & Mean & SD & \\
\hline \multicolumn{6}{|l|}{ Characteristics and sociodemographics } \\
\hline \multicolumn{6}{|l|}{ Age category } \\
\hline Under 40 years old & 68 & 33.0 & 3.39 & 0.61 & 0.429 \\
\hline 40-49 years old & 65 & 31.6 & 3.45 & 0.6 & \\
\hline $50-59$ years old & 47 & 22.8 & 3.45 & 0.75 & \\
\hline $60-69$ years old & 26 & 12.6 & 3.49 & 0.91 & \\
\hline \multicolumn{6}{|l|}{ Education } \\
\hline Junior or senior high school & 79 & 38.3 & 3.36 & 0.68 & 0.381 \\
\hline Vocational school or junior college & 80 & 38.8 & 3.44 & 0.73 & \\
\hline College or graduate school & 45 & 21.8 & 3.58 & 0.59 & \\
\hline Missing & 2 & 1.0 & 3.30 & 0.68 & \\
\hline \multicolumn{6}{|l|}{ Occupation } \\
\hline Part-time employee & 89 & 43.2 & 3.42 & 0.70 & 0.739 \\
\hline Non-regular employee & 5 & 2.4 & 3.24 & 0.43 & \\
\hline Self-employed & 1 & 0.5 & 4.00 & 0.00 & \\
\hline Non-worker & 107 & 51.9 & 3.46 & 0.69 & \\
\hline Missing & 4 & 1.9 & 3.55 & 0.72 & \\
\hline \multicolumn{6}{|l|}{ Self-rated economic status } \\
\hline Low $(1-2)$ & 84 & 40.8 & 3.29 & 0.77 & 0.018 \\
\hline Middle (3) & 86 & 41.7 & 3.52 & 0.54 & \\
\hline $\operatorname{High}(4-5)$ & 35 & 17.0 & 3.61 & 0.71 & \\
\hline Missing & 1 & 0.5 & 3.20 & 0.00 & \\
\hline \multicolumn{6}{|l|}{ Self-rated health status } \\
\hline Low $(1-2)$ & 23 & 11.2 & 3.40 & 0.78 & 0.772 \\
\hline Middle (3) & 41 & 19.9 & 3.41 & 0.66 & \\
\hline High (4-5) & 142 & 68.9 & 3.45 & 0.67 & \\
\hline \multicolumn{6}{|l|}{ Having a primary care physician } \\
\hline Yes & 103 & 50.0 & 3.55 & 0.71 & 0.005 \\
\hline No & 100 & 48.5 & 3.34 & 0.59 & \\
\hline Missing & 3 & 1.5 & 3.00 & 0.75 & \\
\hline \multicolumn{6}{|l|}{ Cancer screening behavior } \\
\hline Undergo breast and/or cervical cancer screening & 57 & 27.7 & 3.50 & 0.55 & 0.605 \\
\hline Do not undergo breast and/or cervical cancer screening & 141 & 68.4 & 3.45 & 0.69 & \\
\hline Missing & 8 & 3.9 & 2.78 & 0.73 & \\
\hline \multicolumn{6}{|l|}{ Health-related behaviors } \\
\hline \multicolumn{6}{|l|}{ Dietary behavior } \\
\hline Well-balanced diet every day & 80 & 38.8 & 3.56 & 0.67 & 0.026 \\
\hline Non-everyday & 118 & 57.3 & 3.39 & 0.64 & \\
\hline Missing & 8 & 3.9 & 2.90 & 0.70 & \\
\hline \multicolumn{6}{|l|}{ Exercise frequency } \\
\hline 2 times or more per week & 38 & 18.4 & 3.65 & 0.73 & 0.025 \\
\hline 1 time or less per week & 160 & 77.7 & 3.42 & 0.63 & \\
\hline Missing & 8 & 3.9 & 2.78 & 0.73 & \\
\hline \multicolumn{6}{|l|}{ Alcohol consumption } \\
\hline Every day & 64 & 31.1 & 3.53 & 0.65 & 0.489 \\
\hline Not every day & 135 & 65.5 & 3.43 & 0.65 & \\
\hline Missing & 7 & 3.4 & 2.74 & 0.73 & \\
\hline
\end{tabular}


Table 1. Continued

\begin{tabular}{lccccc}
\hline & Total & & Health literacy & & "Kruskal-Wallis test" \\
& $\mathrm{N}$ & $\%$ & Mean & SD & $\mathrm{p}$ \\
\hline Smoking behavior & & & & & 0.978 \\
Current smoker & 24 & 11.7 & 3.48 & 0.70 & 0.68 \\
Not current smoker & 181 & 87.9 & 3.43 & 3.20 & 0.00 \\
$\quad$ Missing & 1 & 0.5 & & & \\
SD, standard deviation & & & &
\end{tabular}

SD, standard deviation

Table 2. Relationship of Health Literacy with Cancer Screening Behavior and Health-Related Behaviors

\begin{tabular}{|c|c|c|c|c|c|c|c|c|c|c|}
\hline & \multicolumn{2}{|c|}{$\begin{array}{l}\text { "Cancer screening } \\
\text { behavior (undergo)" }\end{array}$} & \multicolumn{2}{|c|}{$\begin{array}{l}\text { "Dietary behavior } \\
\text { (well-balanced diet } \\
\text { every day)" }\end{array}$} & \multicolumn{2}{|c|}{$\begin{array}{c}\text { "Exercise behavior } \\
\text { (2 times or more per } \\
\text { week)" }\end{array}$} & \multicolumn{2}{|c|}{$\begin{array}{l}\text { "Alcohol consumption } \\
\text { (not everyday)" }\end{array}$} & \multicolumn{2}{|c|}{$\begin{array}{l}\text { "Smoking behavior } \\
\text { (not current smoker)" }\end{array}$} \\
\hline & OR & $95 \% \mathrm{CI}$ & OR & $95 \% \mathrm{CI}$ & OR & $95 \% \mathrm{CI}$ & OR & $95 \% \mathrm{CI}$ & OR & $95 \% \mathrm{CI}$ \\
\hline \multicolumn{11}{|l|}{ Adjustment variables } \\
\hline Age & 1.010 & $0.979-1.042$ & 1.025 & $0.995-1.055$ & 1.060 & $1.021-1.101$ & 1.004 & $0.974-1.035$ & 0.996 & $0.955-1.039$ \\
\hline $\begin{array}{l}\text { Self-rated } \\
\text { economic status }\end{array}$ & 1.292 & $0.905-1.845$ & 1.248 & $0.901-1.728$ & 0.983 & $0.650-1.485$ & 0.927 & $0.664-1.294$ & 1.074 & $0.675-1.709$ \\
\hline $\begin{array}{l}\text { Having a primary } \\
\text { care physician }\end{array}$ & 2.288 & $1.142-4.583$ & 1.124 & $0.598-2.111$ & 0.939 & $0.412-2.140$ & 0.539 & $0.279-1.040$ & 0.893 & $0.357-2.236$ \\
\hline Health literacy & 0.927 & $0.554-1.553$ & 1.350 & $0.835-2.182$ & 1.613 & $0.871-2.989$ & 0.868 & $0.530-1.423$ & 0.906 & $0.464-1.771$ \\
\hline
\end{tabular}

CI, confidence interval; OR, odds ratio

that observed in a nationwide online survey of the general Japanese population $(\mathrm{N}=712$, mean $\pm \mathrm{SD} ; 3.59 \pm 0.62)$ (Ishikawa et al., 2016). The participants in the present study may have had lower health literacy and therefore not been motivated to undergo cancer screening.

Our results indicated no statistically significant relationship of health literacy with adherence to recommendations to undergo breast and/or cervical cancer screening. Rather, such adherence was associated with having a primary care physician. One study suggested that those who underwent periodic health examinations were more likely to both receive and supply instrumental and emotional support in their interactions with others (Mitsuhashi et al., 2006). Such physicians may promote screening behavior by providing informational and emotional support for their patients (Funahashi, 2013). Although only $103(50.0 \%)$ participants in this study had a primary care physician, previous studies related to cancer screening reported approximately $60 \%$ or more of their participants had primary care physicians (Lee et al., 2014; Bhuyan et al., 2017; Tolma et al., 2014; Schoueri-Mychasiw et al., 2013). This partly owes to the lack of a general practitioner system in Japan. Having a primary care physician to support health in workplaces is advisable for encouraging cancer screening.

We also found that a statistically significant association between health literacy and exercise behavior disappeared when controlling for age. In this study, younger participants were more likely to be working compared with older participants (independent t-test, $\mathrm{p}=0.017$; data not shown). Younger participants were also more likely to be in a position of caring for a family member (independent t-test, $\mathrm{p}<0.001$; data not shown). It is therefore plausible that shortage of time due to work and household chores may be an important factor affecting whether insured Japanese women engage in exercise. This may partly explain why exercise behavior was found significantly associated with age rather than health literacy.

Several limitations should be considered in interpreting the results of this study. First, it was a cross-sectional observational study; therefore, we could not determine the casual relationship between participants' health literacy and health-related outcomes, such as adherence to recommendations to undergo breast and cervical cancer screening and health-related behaviors. Second, we collected the data from a single health insurance society. Our sample size was also relatively small, and the response rate was quite low. This raises the concern of selection bias and limited generalizability of our findings. We also only recruited participants who had not received screening even though the society had posted a recommendation for screening in a magazine. It is therefore possible that individuals who were not particularly interested in their own health and had lower health literacy were more likely to be participants in this study. To address these problem, further research with a larger sample is needed to confirm the findings. Third, health literacy and healthrelated behaviors were measured based on self-reported questionnaires. This raises the possibility of participants reporting more favorable health literacy and health-related behaviors, which may have led to overestimation of the health literacy level in this study. Finally, we also asked via self-reported questionnaire whether the participants underwent breast and/or cervical cancer screening. A study on self-reported bias regarding cancer screening 
found individuals were more likely to provide socially desirable answers, which resulted in the over-report of their counseling history (Rauscher et al., 2008). The effect of self-reported bias also cannot be excluded because we confirmed cancer screening behavior based on responses in self-reported questionnaires.

The present study found no statistically significant relationship between health literacy and adherence to recommendations to undergo cancer screening and healthrelated behaviors among insured Japanese women. Rather, cancer screening and health-related behaviors were found related to medical support from physicians and those their own age. Few Japan-based studies have explored the association between health literacy and preventive health behavior among insured Japanese women, and additional studies are needed to further verify these associations.

\section{Acknowledgements}

The author(s) declared no potential conflicts of interest with respect to the research, authorship, and/or publication of this article. This study was funded by JSPS KAKENHI Grant Number 16H05211. We would like to thank all participants in this study.

\section{References}

Bhuyan SS, Chandak A, Gupta N, et al (2017). Patient-provider communication about prostate cancer screening and treatment: new evidence from the Health Information National Trends Survey. Am J Mens Health, 11, 134-46.

Davey J, Holden CA, Smith BJ (2015). The correlates of chronic disease-related health literacy and its components among men: a systematic review. BMC Public Health, 15, 589.

Delanoë A, Lépine J, Leiva Portocarrero ME, et al (2016). Health literacy in pregnant women facing prenatal screening may explain their intention to use a patient decision aid: a short report. BMC Res Notes, 9, 339.

Di J, Rutherford S, Chu C (2015). Review of the cervical cancer burden and population-based cervical cancer screening in China. Asian Pac J Cancer Prev, 16, 7401-7.

Duong VT, Lin IF, Sorensen K, et al (2015). Health literacy in Taiwan: a population-based study. Asia Pac J Public Health, 27, 871-80

Funahashi H (2013). Attributes of non-participants aged 40-59 years in specific health check-ups. Nihon Koshu Eisei Zasshi, 60, 119-27.

Furuya Y, Kondo N, Yamagata Z, Hashimoto H (2013). Health literacy, socioeconomic status and self-rated health in Japan. Health Promot Int, 30, 505-13.

Ishikawa H, Kato M, Kiuchi T (2016). Associations of health literacy and information sources with health-risk anxiety and protective behaviors. J Commun Health, 9, 33-9.

Ishikawa H, Nomura K, Sato M, Yano E (2008). Developing a measure of communicative and critical health literacy: a pilot study of Japanese office workers. Health Promot Int, 23, 269-74.

Kim K, Han HR (2016). Potential links between health literacy and cervical cancer screening behaviors: a systematic review. Psychooncology, 25, 122-30.

Lee S, Chen L, Jung MY, Baezconde-Garbanati L, Juon HS (2014). Acculturation and cancer screening among Asian Americans: role of health insurance and having a regular physician. J Community Health, 39, 201-12.
Liu YB, Liu L, Li YF, Chen YL (2015). Relationship between health literacy, health-related behaviors and health status: a survey of elderly Chinese. Int J Environ Res Public Health, 12, 9714-25.

Matsumoto H, Sakai K, Tokoro M, et al (2004). Relationship between the self-rated health and self-efficacy for health behavior among Japanese young women. Bull Mukogawa Womens Univ Humanities Social Sci, 52, 105-10.

Mitsuhashi Y, Kishi R, Eguchi T, et al (2006). Study of influences of social support and social networks on participation in periodic health extermination of the elderly at home. Jpn J Public Health, 53, 92-104.

Myers ER, Moorman P, Gierisch JM, et al (2015). Benefits and harms of breast cancer screening: a systematic review. JAMA, 314, 1615-34.

Nutbeam D (1998). Health promotion glossary. Health Promot Int, 13, 349-64.

Nutbeam D (2000). Health literacy as a public health goal: a challenge for contemporary health education and communication strategies into the 21 st century. Health Promot Int, 15, 259-67.

OECD. Stat. Health status. Available from: http://stats.oecd. org/Index.aspx?DatasetCode=HEALTH_STAT\#. Accessed 18 Dec 2017.

Oldach BR, Katz ML (2014). Health literacy and cancer screening: a systematic review. Patient Educ Couns, 94, 149-57.

Rauscher GH, Johnson TP, Cho YI, Walk JA (2008). Accuracy of self-reported cancer-screening histories: a meta-analysis. Cancer Epidemiol Biomarkers Prev, 17, 748-57.

Schoueri-Mychasiw N, McDonald PW (2013). Factors associated with underscreening for cervical cancer among women in Canada. Asian Pac J Cancer Prev, 14, 6445-50.

Tolma EL, Stoner JA, Li J, Kim Y, Engelman KK (2014). Predictors of regular mammography use among American Indian women in Oklahoma: a cross-sectional study. $B M C$ Womens Health, 14, 101.

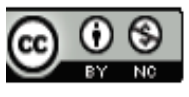

This work is licensed under a Creative Commons AttributionNon Commercial 4.0 International License. 